DOI 10.37882/2223-2982.2021.11.37

\title{
РУССКИЕ ГЛАГОЛЫ ДВИЖЕНИЯ И СТРАТЕГИИ ИХ ИЗУЧЕНИЯ В КИТАЙСКОЙ АУДИТОРИИ (НА МАТЕРИАЛЕ РУССКИХ ПЕСЕН)
}

\section{RUSSIAN VERBS OF THE MOVEMENT AND STRATEGIES OF THEIR STUDY IN THE CHINESE AUDIENCE (ON THE MATERIAL OF RUSSIAN SONGS) Zheng Zhongyi}

Summary: Of the total number of verbs in Russian, the verbs of movement play an important role. They are widely used in teaching the Russian language, and often difficulties arise in the process of studying them. In this article, based on the material of Russian songs, the verbs of movement associated with the general denotative component of the meaning "movement of the subject in space" $[1,62]$ are considered in order to demonstrate the most effective way of teaching verbs of movement in the RFL lessons in the Chinese audience.

Keywords: verb, RFL methodology, Russian songs.

\author{
Чжэн Чжуньи \\ аспирант, Ассистент, Казанский Федеральный \\ Университет, г. Казань \\ zhongyi2017@mail.ru
}

Аннотация: Из всего количества глаголов в русском языке глаголы движения играют важную роль. Они широко используются в преподавании русского языка, и часто в процессе их изучения возникают трудности. В данной статье на материале русских песен рассматриваются глаголы движения, связанные с общим денотативным компонентом значения «перемещение субъекта в пространстве» $[1,62]$, чтобы продемонстрировать наиболее эффективный способ обучения глаголам движения на занятиях РКИ в китайской аудитории.

Ключевые слова: глагол, методика РКИ, русские песни.

\section{Введение}

$\mathrm{y}$ ченые часто обращаются к произведениям устного народного творчества, чему не стоит удивляться: «...в современной социокультурной ситуации он (традиционный фольклор) оказывается одним из особых носителей исторической памяти, и в том качестве способен на своеобразие художественно-образное представление многообразия культурно-исторической судьбы народа», достоверно замечают современные исследователи $[2,55]$.

Соответственно, мы пытаемся найти эффективный метод в преподавании русского языка и дать китайским обучающимся практические рекомендации по изучению глаголов движения на материале русских народных песен.

\section{Обзор ^итературы}

Каждый научный труд должен иметь под собой почву, опору в виде философских, психологических, исторических, религиозных или иных трактатов, исследований. Теоретической основой и методологической базой данного исследования послужили труды Э.А. Балалыкиной, А.И. Кузнецовой, Н.Ю. Шведовой [Балалыкина, 2006; Кузнецова, 1980; Шведова, 1980], посвященные исследованию глаголов движения как части речи русского языка; труды Г.А. Битехиной, Л.С. Муравьевой, Л.П. Юдиной, исследующие употребление глаголов движения в русском языке [Битехина, 1966]; также интерес представляют методические рекомендации по аспектному обучению и изучению глаголов движения иностранными гражданами, описывающие: трудные вопросы русской грамматики для иностранцев [Метс, 2010], глаголы движения в русском языке и особенности их преподавания в китайской аудитории [Корчик, 2012], глаголы движения в русском языке (например, сборник таблиц и упражнений для слушателей подготовительного отделения) [Унченко, 2013] и глаголы движения и стратегии обучения на начальном этапе [Куриленко, 2018].

\section{Материалы и методы}

Материалом для данной статьи послужили тексты из русских народных и детских песен.

В статье использовались общенаучные и языковедческие методы исследования: описательный, контекстуальный и аналитический метод; метод систематизации и классификации. Основным методом является метод лингвистического наблюдения.

\section{Результаты исследования}

Результаты исследования могут найти применение в качестве инструмента для отработки навыков употребления в речи глаголов движения на занятиях по обучению русскому языку как иностранному.

Глагол - часть речи, обладающая обобщенным значением движения. Это значение глагол выражает в грам- 
матических категориях вида, залога, наклонения, времени и лица. Глагол - самая сложная и самая богатая по системе форм (и их значений) часть речи, обладающая максимальным количеством грамматических категорий. В отличие от существительных или прилагательных, которые имеют три грамматических категории: рода, числа и падежа, у глагола - 7 грамматических категорий $[3,5]$.

Из всего количества глаголов в русском языке глаголы движения играют важную роль. Глаголы движения во всех языках обозначают важнейшее понятие - движение - наиболее поразительный феномен мира $[4,408]$. В соответствии с этим, особое внимание при изучении русских глаголов движения на занятиях РКИ объясняется тем, что глаголы движения являются базой, без которой невозможна полноценная коммуникация.

Шведова Н.Ю. в книге «Русская грамматика» пишет: «...глаголы движения - устойчивая структурно-семантическая группа глаголов несовершенного вида, обладающая специфическими характеристиками, присущими только этой группе, на уровне морфологии, синтаксиса, а также на уровне функционирования» $[5,591]$.

Как известно, глаголы движения широко используются в преподавании русского языка, и часто в процессе их изучения возникают трудности, поэтому важно определить их специфику, дать анализ функционирования глаголов движения в речи. В китайском языке нет проблем с ориентированием глаголов движения, но в русском языке много разных аспектов использования данных глаголов, из-за этой разницы при коммуникации часто возникают ошибки. Соответственно, изучая глаголы движения, следует обращать внимание на эти вопросы, избегая неправильного употребления глагола направленного и ненаправленного движения. В данной статье на материале русских песен рассматриваются глаголы движения, связанные с общим денотативным компонентом значения “перемещение субъекта в пространстве" [1, 62].

По словам Метсом Н.А., группу глаголов движения в русском языке составляют 18 пар глаголов, которые указывают на один и то же тип перемещения, но при этом оба являются глаголами несовершенного вида. Следует отметить, что последние четыре пары находятся на периферии системы глаголов движения и специально не вводятся в практический курс РКИ. По этой причине, анализируя трудности, связанные с глаголами движения, остановимся на 14 парах глаголов движения, которые представлены практически во всех учебных пособиях по русской грамматике РКИ [6].

Корчик Л.С. в числе трудностей, возникающих при изучении глаголов движения в иностранной аудитории, отмечает следующие:

1. «богатство лексических значений глаголов движения;

2. необходимость разграничивать обозначение движения с помощью транспорта и без него;

3. наличие бесприставочных и приставочных глаголов движения;

4. существование среди приставочных глаголов несовершенного вида глаголов, обозначающих однонаправленное и ненаправленное, однократное и повторяющееся движение;

5. среди приставочных глаголов - употребление парных и несоотносительных по виду глаголов, глаголов с многочисленными различными приставками, часто довольно близкими по значению» $[7,84]$.

Таблица 1

Глаголы движения русского языка

\begin{tabular}{|l|l|l|}
\hline Непереходные глаголы & Переходные глаголы & Возвратные глаголы \\
\hline Идти-ходить & Вести-водить & Катиться-кататься \\
\hline Ехать-ездить & Везти-водить & нестись-носиться \\
\hline Бежать-бегать & Нести-носить & тащиться-таскаться \\
\hline Лететь-летать & катить-катать & гнаться-гоняться \\
\hline Плыть-плавать & тащить-таскать & \\
\hline Брести-бродить & Гнать-гонять & \\
\hline Лезть-лазить & & \\
\hline Ползти-ползать & & \\
\hline
\end{tabular}

Таким образом, в связи с этими причинами, мы хотим дать китайским учащимся несколько прилагаемых стратегий изучения глаголов движения на материале русских песен.

Как известно, глаголы однонаправленного движения выражают движение в одном направлении, как правило, к определенной цели. Они употребляются в ряде контекстов, которые говорящий определяет исходя из ситуации, которую он хочет описать, или из текстового окружения этого предложения. Мы можем предлагать рассматривать это на материале песен на занятиях, потому что китайцы любят и умеют петь, хорошо запоминают и проч. Например, Мы едем, едем, едем В далёкие края и Мы ехали, мы пели («Мы едем, едем, едем...») [8, электронный ресурс]. В данном предложении речь идет о конкретном действии, исследуемом в данный момент, предсказываемом в специфический момент в прошлом или запланированном на ближайшее будущее; Но тут лиса бежала А может, не бежала («А может быть ворона...») [8, электронный ресурс]. Здесь однонаправленное движение обозначает продолжительность действия; Ёжик резиновый Шёл и нас выстывал Дырочкой в правом боку («Ёжик резиновый») [8, электронный ресурс]. В этом случае однонаправленное движение указывает на краткое движение. Я иду и пою Обо всём хорошем («Неприятность эту мы переживём») [8, электронный ресурс]. 
В данном предложении движение включено в цепочку сменяющих друг друга действий, образующих регулярно или многократно повторяющееся обстоятельство.

В контекстах глаголов неоднонаправленного движения говорящему необходимо назвать движение, происходящее или происходившее в разных направлениях, или движение как таковое. Контексты глаголов неоднонаправленного движения являются следующими:

1. Движение в разных направлениях:

- Движение «туда - обратно»: В воскресенье я на ярмарку ходила А во вторник я в банюшку ходила («Неделька») [8, электронный ресурс].

- Движение в разных направлениях: По той по дороженьке офицер часто ходил Офицер часто ходил, на окошечко глядел («Барыня, барыня, сударыня барыня!») [8, электронный ресурс].

2. Движение без определенной цели: Хорошо бродить по свету с карамелькой за щекой Хорошо бродить по улице («Песенка фунтика») [8, электронный ресурс].

3. Общая способность к осуществлению движения какого-либо типа: Носорог, рог, рог идёт Крокодил, дил, дил плывёт («Песенка львёнка и черепахи») [8, электронный ресурс] и Так что прежде, человечек Выучись ходить («Точка, точка, запятая») [8, электронный ресурс].

4. Повторяющееся движение: Что ты часто ходишь на дорогу Не ходи так часто на дорогу («Письмо к матери») [8, электронный ресурс].

Надо обратить внимание на то, что у глаголов бродить, катать, кататься, носиться, гоняться отсутствует значение движения «туда-обратно». Ср: Мы ходили/бродили по лесу и Вчера мы ходили в лес при невозможности * бродить в лес.

По мнению некоторых ученых, «... в практике преподавания русского языка как иностранного традиционно выделяют два относительно самостоятельных аспекта: употребление ГД без приставок и употребление ГД с приставками» [9]. Таким образом, затруднения при изучении глаголов движения могут возникать вследствие наличия бесприставочных и приставочных глаголов. Употребление глаголов движения без приставок в текстах песен представлены выше. Далее следует проанализировать употребление глаголов движения с приставками.

Более 20 продуктивных префиксов (в-, вы-, за-, у-, по-, при-...) используются с глаголами движения в русском языке. В соответствии с этим на занятиях для китайских учащихся мы можем привести примеры из русских песен и объяснить значение приставочных глаголов движения с помощью рисунков.
1) Префикс По- от однонаправленных и от разнонаправленных глаголов движения образует новые глаголы совершенного вида: идти-пойти $(\mathrm{CB})$, ходить-походить (СВ) и др. [11, 34]

Таблица 2

\begin{tabular}{l|l|} 
По- + однонаправленные глаголы & По- + разнонаправленные глаголы \\
\hline $\begin{array}{l}\text { Обозначение начала движения в } \\
\text { одном направлении }\end{array}$ & $\begin{array}{l}\text { Обозначение продолжительности } \\
\text { разнонаправленного движения }\end{array}$ \\
$\begin{array}{l}\text { Пример: } \\
\text { Пойдем, пойдем, Дуня, пойдем, } \\
\text { Дуня Пойдем Дуня, во лесок, во } \\
\text { лесок («Во кузнице») } \\
\text { [8, электронный ресурс]. }\end{array}$ & $\begin{array}{l}\text { Пример: } \\
\text { Походить бы мне по травкам } \\
\text { Походить бы по муравкам } \\
\text { («Походить бы мне по травкам») } \\
\text { [10, электронный ресурс]. }\end{array}$ \\
\hline
\end{tabular}

2) Глаголы движения с префиксами При- и У- в прошедшем времени.

Таблица 3

\begin{tabular}{|l|l|}
\hline \multicolumn{1}{|c|}{ НСВ } & \multicolumn{1}{c|}{ СВ } \\
\hline $\begin{array}{l}\text { Приходил = субъект был и уже } \\
\text { ушёл: } \\
\text { Ко мне нонче друг Ванюша при- } \\
\text { ходил («У нас нонче суббота») [8, } \\
\text { электронный ресурс]. }\end{array}$ & $\begin{array}{l}\text { Пришёл = субъект сейчас здесь: } \\
\text { Но вот однажды осенью Пришёл } \\
\text { любви конец («Бывали дни весе- } \\
\text { лые...») [8, электронный ресурс]. }\end{array}$ \\
\hline $\begin{array}{l}\text { Уходил = субъекта не было, но он } \\
\text { уже вернулся: }\end{array}$ & $\begin{array}{l}\text { Ушёл = сейчас субъекта здесь нет: } \\
\text { Товарищ ушёл ... Лопату схватил } \\
\text { («Раскинулось море широко») [8, } \\
\text { электронный ресурс]. }\end{array}$ \\
\hline
\end{tabular}

Приставки, которые присоединяются к глаголам движения, делятся на две группы: 1) приставки пространственного значения, конкретизирующие направление движения в пространстве. В эту группу входят такие пары, как: приехать-приезжать, уехать-уезжать и др. Эти глаголы движения с приставками пространственного значения составляют видовые пары, в которых глагол совершенного вида всегда образуется от глагола однонаправленного движения, например, идти-прийти, ехать-приехать и др., а глагол несовершенного вида может образовываться либо от соответствующего глагола неоднонаправленного движения, как ходить-приходить, летать-улетать и др., либо от основы отличной от соответствующего бесприставочного движения: ездить-приезжать, плавать-переплывать и др. Примеры показаны в втором пункте. 2) приставки непространственного значения, характеризующие движение по времени, интенсивности или результативности. Они присоединяются к глаголам неоднонаправленного движения. При этом образуются глаголы совершенного вида, как правило, не имеющие приставочной видовой 
пары несовершенного вида. Например:

1. Префикс по- выражает значение начала действия и значение «немного». В значении «немного» она присоединяется к глаголам неоднонаправленного движения для передачи:

- неоднонаправленного движения, характеризующегося небольшой продолжительностью: Походить бы мне по травкам Походить бы по муравкам («Походить бы мне по травкам») [10, электронный ресурс].

- движения, направленного «туда-обратно», ограниченного по количеству повторений: Походить по тетушкам, по дядюшкам («Девичник») [12, электронный ресурс].

Следует отличать это значение приставки по- от значения начала действия. Префикс по-, выражающая начало действия, присоединяется к глаголам однонаправленного движения. Ср: Походить бы мне по травкам Походить бы по муравкам («Походить бы мне по травкам») [10, электронный ресурс] и Пошли девки на работу На работу, Кума, на работу («На работу, кума, на работу») [8, электронный ресурс].

2. Префикс с- обозначает однократное движение к цели и обратно: Я пойду - схожу к дружку Иванушке («Не сырой ли дубик разгорается») [8, электронный ресурс]. Этот префикс не присоединяется к глаголам носить(ся), бродить, таскать(ся).

3. Префикс за- обозначает начало неоднонаправленного движения: Разрыл я сугроб-то и к месту прирос Мороз заходил под тулупом («Когда я на почте служил ямщиком») [8, электронный ресурс]. С помощью этого префикса в начинательном значении образуются только глаголы заходить, забегать, заплавать, залетать.

\section{ОбсужАение и заключения}

Таким образом, для достижения коммуникативных умений китайских студентов, уменьшения случаев интерференций и, следовательно, исправления типовых ошибок необходимо учитывать особенность глаголов движения. С этой целью предлагается использовать результаты анализа прилагаемых стратегий в системе упражнений и формулировках правил.

Кроме того, мы можем сделать сопутствующие выводы: - Мы придерживаемся точки зрения ряда методистов в том, что использование в качестве иллюстративного материала текстов русских песен представляет наиболее эффективный способ обучения глаголам движения на занятиях РКИ в китайской аудитории, который в условиях жесткого лимита времени позволяет максимально облегчить восприятие учебного материала учащимися и повысить скорость формирования не только грамматических, но и коммуникативных навыков и умений у студентов при обучении русскому языку как иностранному $[13,20]$.

- Изучение русских глаголов движения и их употребления в языке и речи можно интересно подать с позиций этноориентированного подхода к обучению РКИ.

Таким образом, русская грамматика, которая преподносится сквозь призму русского песенного материала, помогает не только уяснить теоретический материал и отработать его на практике, но и познакомиться с выдающейся российской культурой.

\section{ЛИТЕРАТУРА}

1. Барцева Л.И., Матросова Л.С., Музурова Н.А. Глаголы движения в романе С.Г. Чавайна «Элнет» // Вестник Марийского государственного университета. 2015. C. 62-65.

2. аминская Е.А. Актуализация традиционного фольклора в современной социокультурной среде на основе его имманентных характеристики // Вестник славянских культур. 2016. С. 53-64.

3. Балалыкина Э.А. Современный русский язык. Морфология. Часть ІІ: Глагол. Служебные части речи. Междометия. Модальные слова. - Казань: Изд-во Казанск. ун-та, 2006. - 180 с.

4. Кузнецова А.И., Хелимский Е.А., Грусикина Е.В. Очерки по селькупскому языку. Тазовский диалект. - М.: изд-во МГУ, 1980. - 408 с.

5. Шведова Н.Ю. Русская грамматика. - М.: Наука, 1980. - Т.1: Фонетика. Фонология. Ударение. Интонация. Словообразование. Морфология. - 789 с.

6. Метс Н.А. Трудные аспекты русской грамматики для иностранцев. - М.: ИКАР. 2010.

7. Корчик Л.С. Глаголы движения в русском языке и особенности их преподавания в китайской аудитории. Вестник РУдН. Серия: Вопросы образования: языки и специальность. 2012. С. 84 - 90.

8. Русские народные песни [Электронный ресурс]. - Режим доступа: https://pesni.retroportal.ru/np.shtml

9. Битехина Г.А., Муравьева Л.С., Юдина Л.П. Употребление глаголов движения в русском языке. - М.: Изд-во Моск. ун-та, 1966.

10. «Походить бы мне по травкам» [Электронный ресурс]. - Режим доступа: https://feb-web.ru

11. Унченко В.В., Хозяйкина Н.В. Глаголы движения русского языка (сборник таблиц и упражнений слушателям подготовительного отделения для иностранных граждан) / Сост.: В.В. Унченко, Н.В. Хозяйкина. - Д.: Национальный горный университет, 2013. - 53 с. 
12. «Девичник» [Электронный ресурс]. - Режим доступа: https://flirtyem.ru

13. Куриленко В.Б., Щербакова О.М., Бирюкова Ю.Н. Глаголы движения: стратегии обучения на начальном этапе. Вестник РудН. Серия: Здоровье и образование в XXI веке. 2018. ( $14-20$.

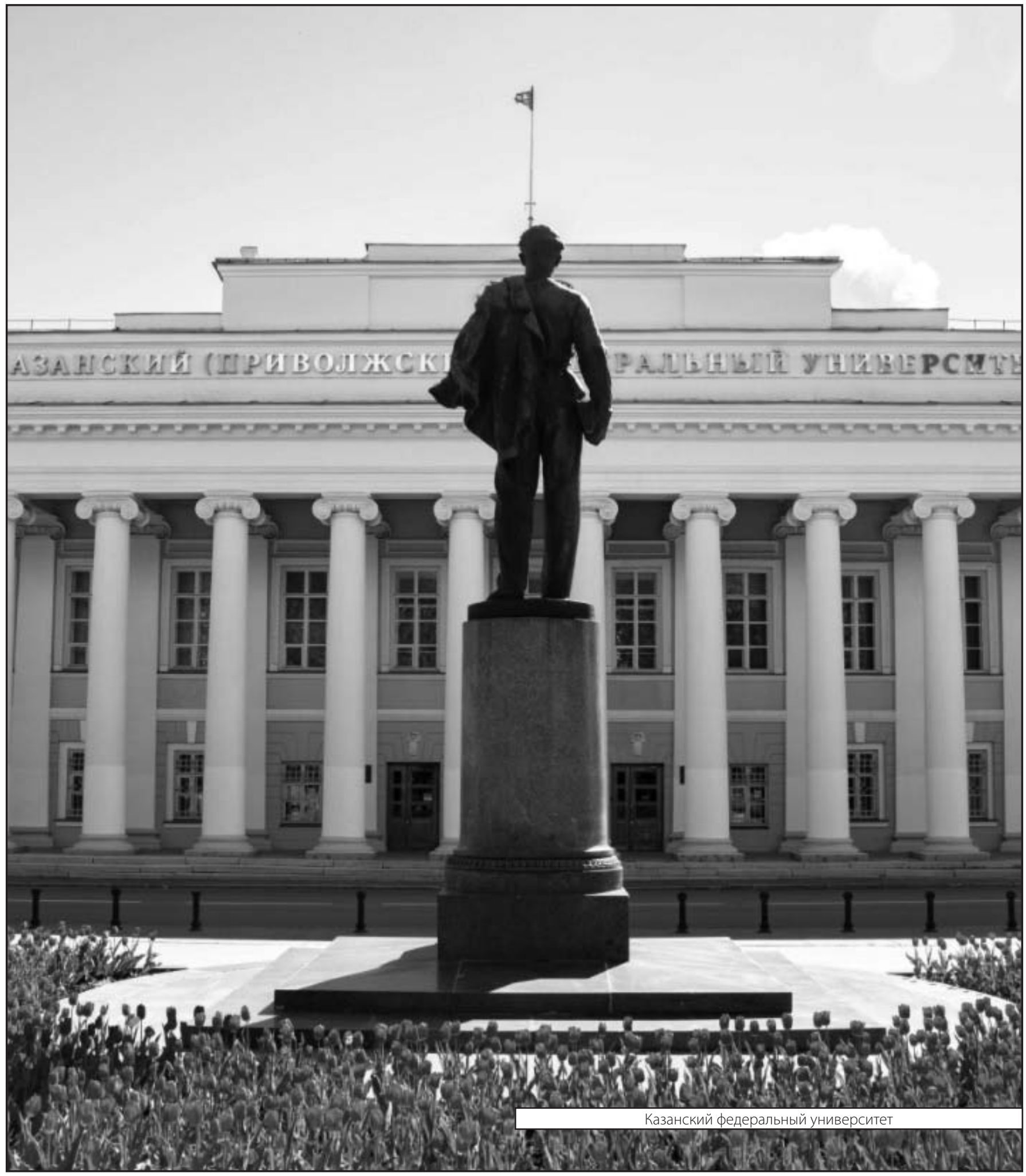

